\title{
The Relationship between Bradycardia, Apnea, and Hypoxemia in Preterm Infants
}

\author{
CHRISTIAN F. POETS, VALERIE A. STEBBENS, MARTIN P. SAMUELS, AND
}

DAVID P. SOUTHALL

\begin{abstract}
Department of Paediatric Pulmonology, Medical School, Hannover, Germany [C.F.P.], and the Academic Department of Paediatrics, North Staffordshire Hospital Centre, University of Keele, Stoke-on-Trent, United Kingdom [V.A.S., M.P.S., D.P.S.]
\end{abstract}

\begin{abstract}
The pathogenesis of bradycardias in preterm infants is poorly understood. Because their pathogenesis may involve both apnea and hypoxemia, we set out to analyze the proportion of bradycardias that were associated with an apneic pause and/or a fall in arterial oxygen saturation $\left(\mathrm{SaO}_{2}\right)$, and the temporal sequence of the three phenomena, in overnight tape recordings of $\mathrm{SaO}_{2}$ (Nellcor $\mathrm{N} 100$ in beat-to-beat mode), breathing movements, nasal airflow, and ECG in 80 preterm infants at the time of discharge from hospital. A bradycardia was defined as a fall in heart rate of $\geq 33 \%$ from baseline for $\geq 4 \mathrm{~s}$, an apneic pause as a cessation of breathing movements and/or airflow for $\geq 4 \mathrm{~s}$, and a desaturation as a fall in $\mathrm{SaO}_{2}$ to $\leq \mathbf{8 0 \%}$. A total of 193 bradycardias were found in $46(58 \%)$ of the recordings (median, three per recording; range 1-18). There was a close relationship between bradycardias, apneic pauses, and desaturations: $83 \%$ of bradycardias were associated with apneic pauses and $86 \%$ with desaturations. Where all three phenomena occurred in combination, the time from the onset of apnea to the onset of the fall in $\mathrm{SaO}_{2}$ was shorter (median interval, $0.8 \mathrm{~s}$; range -4.9 $+11.5 \mathrm{~s}$ ) than that from the onset of apnea to the onset of bradycardia (median, $4.8 \mathrm{~s}$; range $-4.0-+14.0 \mathrm{~s}$ ). Hence, most bradycardias $(86 \%)$ commenced after the onset of the fall in $\mathrm{SaO}_{2}$. We conclude that bradycardia, apnea, and hypoxemia are closely linked phenomena in preterm infants. (Pediatr Res 34: 144-147, 1993)
\end{abstract}

\section{Abbreviations}

$\mathrm{SaO}_{2}$, arterial oxygen saturation

GA, gestational age

IHR, instantaneous heart rate

$I Q R$, interquartile range

Recurrent episodes of bradycardia constitute a considerable problem in the clinical management of preterm infants. They can be associated with severe hypoxemia (1) and with significant reductions in cerebral blood flow (2) and may be a predisposing factor in the development of periventricular leucomalacia (3). Their pathogenesis, however, is poorly understood.

Earlier studies suggested that the bradycardia resulted from a chemoreceptor reflex elicited by the rapid development of hypoxemia during apnea $(4,5)$. Subsequent investigators, however,

Received October 22, 1992; accepted March 1, 1993.

Correspondence and reprint requests: Dr. C. F. Poets, Kinderklinik, Medizinische Hochschule Hannover $\mathrm{K}$ Gutschow Str. 8, D-W-3000 Hannover 61, FRG.

Supported by Little Ones, Babes in Arma, Cot Death Research, and the Priory Foundation. Dr. Poets was supported by the Deutsche Forschungsgemeinschaft. Bonn, FRG. claimed that the fall in heart rate commenced too early during the course of the apneic pause to be attributed to apnea-induced hypoxemia, and suggested instead that bradycardias were caused by a reflex response to the cessation of lung inflation $(6,7)$. These studies did not measure oxygenation continuously, so both hypotheses remained essentially speculative. In 1986, HendersonSmart et al. (8) recorded $\mathrm{SaO}_{2}$ during episodes of apnea and bradycardia in five preterm infants, using an ear oximeter with an electronic response time of $0.1 \mathrm{~s}$. They reported that the interval between the onset of apnea and the onset of the fall in $\mathrm{SaO}_{2}$ was shorter than that between the onset of apnea and the onset of bradycardia and concluded that the bradycardias occurred as a response to a fall in $\mathrm{SaO}_{2}$. This conclusion, however, was recently challenged by Upton et al. (9), who warned, appropriately, against inferring a cause-and-effect relationship from observations on the temporal relationship between hypoxemia and bradycardia. Unfortunately, these latter authors used a pulse oximeter that averaged the $\mathrm{SaO}_{2}$ readings over $6 \mathrm{~s}$, making it difficult to comment on the temporal relationship between hypoxemia and bradycardia.

In this study, we set out to analyze further the temporal relationships between bradycardia, apnea, and hypoxemia. Two specific questions were addressed: 1) How frequently is a bradycardia associated with an apneic pause and/or a fall in $\mathrm{SaO}_{2}$ ? and 2) What is the temporal sequence of the three phenomena?

\section{PATIENTS AND METHODS}

Patients. We have recently reported data for baseline $\mathrm{SaO}_{2}$ and the frequency of episodic desaturation in a group of 160 preterm infants at discharge from hospital (10). These infants were broadly representative of all preterm infants discharged from three special care baby units in northern England during a 1-yr period. Eighty randomly selected infants from this group had undergone simultaneous recordings of ECG, and their recordings were used in the present study. There were 46 boys and 34 girls. Their mean GA at birth was $32.5 \mathrm{wk}$ (SD $2.6 \mathrm{wk}$ ), and at the time of study $36.3 \mathrm{wk}$ (SD $2.3 \mathrm{wk}$; mean postnatal age $27 \mathrm{~d}$, SD $28 \mathrm{~d}$ ). Twenty-one infants were born between 26 and 31 wk GA, 24 between 32 and $33 \mathrm{wk}$, and 35 between 34 and $36 \mathrm{wk}$. Their mean birth weight was $1892 \mathrm{~g}$ (SD $547 \mathrm{~g}$ ), and mean weight at the time of study was $2236 \mathrm{~g}$ (SD $330 \mathrm{~g}$ ). Forty-two infants had experienced some degree of respiratory distress syndrome after birth, 25 having received intermittent positive-pressure ventilation, and 25 had a history of apnea of prematurity. All infants were considered well at the time of the recording, and none was receiving additional inspired oxygen, theophylline, or other cardiotropic drugs.

Recordings. The infants underwent overnight recordings of $\mathrm{SaO}_{2}$ (Nellcor N100 with new software equivalent to N200 and modified to provide beat-to-beat data; Nellcor Inc., Haywood, CA), photoplethysmographic (pulse) wave forms from the oxi- 
meter for the validation of the $\mathrm{SaO}_{2}$ signal, breathing movements via volume expansion capsule (Graseby Dynamics, Watford, UK) or inductance plethysmography (Studley Data Systems, Oxford, UK), nasal airflow via thermistor (Yellow Springs Instruments, Yellow Springs, OH), and ECG (in a modified lead 2 position). The oximeter sensor was taped around the right or left big toe. The recordings were stored on tape (Racal FM4, Southampton, UK) and subsequently printed (including the IHR signal derived from the ECG) onto graph paper (at $3.1 \mathrm{~mm} / \mathrm{s}$ ).

Data analysis. The printouts were analyzed manually by three experienced workers without knowledge of the infants' clinical histories. Baseline IHR and $\mathrm{SaO}_{2}$ values were determined during the pattern of regular breathing, as described previously $(11,12)$; in summary, the baseline $\mathrm{SaO}_{2}$ and IHR values were measured at end-inspiration for each of five successive breaths and for each of 10 successive heart beats, respectively, in the middle of each episode of regular breathing, at least $10 \mathrm{~s}$ away from sighs or apneic pauses.

A bradycardia was defined as a fall in heart rate of $\geq 33 \%$ from baseline, lasting for $4 \mathrm{~s}$ or longer. The number of bradycardias was counted for each recording, and, in each episode, the time the IHR remained below the bradycardia threshold and the lowest rate reached were measured. A desaturation was defined as a fall in $\mathrm{SaO}_{2}$ to $80 \%$ or less (12). The number of desaturations was also counted for each recording.

The bradycardias were then classified according to their relationship with (l) a desaturation and (2) an apneic pause of $4 \mathrm{~s}$ or longer, the latter being divided into pauses that showed a cessation of both breathing movements and airflow ("central" apnea), and pauses that, either in addition or exclusively, involved a cessation of airflow with continuous breathing movements ("mixed" or "obstructive" apnea). An association with a desaturation and/or an apneic pause was considered present if either commenced within $\pm 15 \mathrm{~s}$ of the onset of the bradycardia, both intervals being arbitrarily defined from pilot data. The following intervals were measured: $l$ ) the times elapsing from $a$ ) the onset of apnea to the onset of bradycardia, $b$ ) the onset of apnea to the onset of desaturation, and $c$ ) the onset of desaturation to the onset of bradycardia; and 2) the durations of $a$ ) the apneic pauses and $b$ ) the desaturations associated with bradycardias (from the end of the last inspiration preceding the pause to the beginning of the first inspiration following it, and from the time $\mathrm{SaO}_{2}$ fell to $\leq 80 \%$ until values $>80 \%$ were regained, respectively).

Correction of measurements for lung-toe circulation time. Any change in pulmonary venous $\mathrm{SaO}_{2}$ was measured by the pulse oximeter with a delay, resulting from blood travelling from the lung to the toe. This lung-toe circulation time was calculated from the delay observed between the onset of the first breath after an apneic pause and the beginning of recovery from the associated desaturation $(1,13)$ (Fig. 1). Measurements of the intervals between apnea/bradycardia and the associated desaturation were corrected by subtracting this delay. However, because bradycardia may affect circulation time, these measurements had to be performed on desaturations that were not associated with bradycardia. We therefore identified all desaturations associated with apneic pauses, but without bradycardia, and measured the delay times in these desaturations. However, in recordings where the number of desaturations associated with periodic apnea exceeded 20 , the number of desaturation measurements performed in this pattern was limited to 20 by using a systematic sampling procedure. We then calculated the median of the delay times observed during these desaturations for each recording to provide an estimate of each infant's lung-toe circulation time.

Statistical analysis. Means and SD or, where appropriate, medians, ranges, and IQR were calculated for each variable. Statistical significance of the data comparisons was assessed using the unpaired $t$ test.

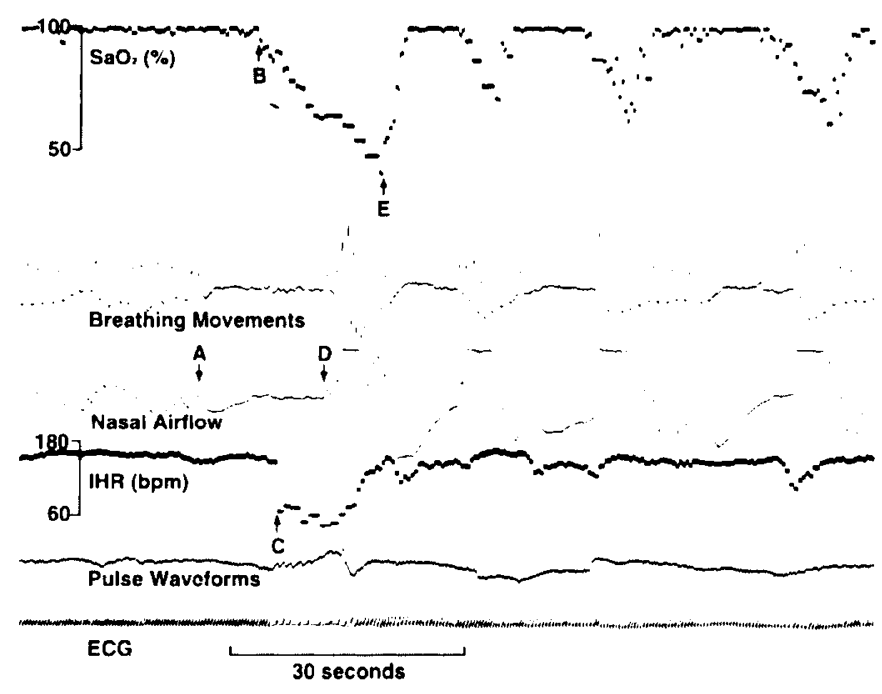

Fig. 1. Example of a bradycardia (a fall in IHR to $50 \mathrm{bpm}$ ), which is associated with both an apneic pause, lasting $17 \mathrm{~s}$, and a fall in $\mathrm{SaO}_{2}$ to $42 \%$. The temporal relationships were assessed by measuring the intervals between the onset of apnea and that of desaturation ( $A$ to $B$ ), between the onset of desaturation and that of bradycardia $(B$ to $C)$, and between the onset of apnea and that of bradycardia $(A$ to $C$ ). The first two intervals were then corrected for the delay caused by the time it took the blood to travel from the lung to the toe, which was calculated from the delay observed between the first breath after a pause and the beginning of recovery from the associated desaturation ( $D$ to $E$; demonstrated here during bradycardia, but analyzed in the study only during desaturations not associated with bradycardia).

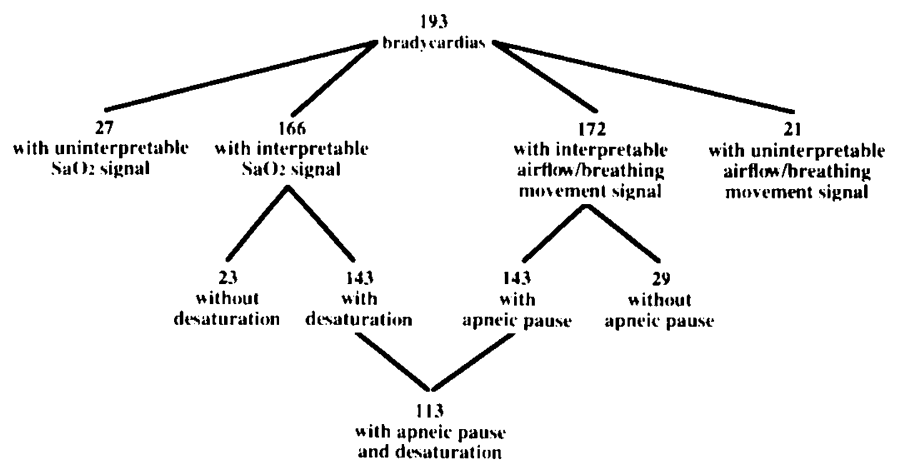

Fig. 2. Number of bradycardias and their associated $\mathrm{SaO}_{2}$ and breathing patterns.

\section{RESULTS}

The mean duration of recording was $12.5 \mathrm{~h}$ (SD 0.8). The median baseline heart rate was 149 bpm (range 119-184); the bradycardia threshold varied between 79 and 122 bpm (median 99, IQR 95-103). The median baseline $\mathrm{SaO}_{2}$ (measured during regular breathing) was $99.6 \%$ (range $93.2-100$ ). A total of 7311 desaturations was found in 78 of the 80 recordings; the median frequency for the total group was 49 desaturations per recording (range 0-501).

Bradycardias and associated breathing/Saon patterns. A total of 193 bradycardias were found in 46 of the 80 infants investigated (median three/recording, range 1-18, IQR 1-6). Infants who showed bradycardias were born earlier [mean GA $31.8 \mathrm{wk}$ (SD 2.7) versus $33.4 \mathrm{wk}$ (SD 2.3), $p<0.01$ ] than those who did not have bradycardias in their recordings. GA at the time of recording, however, was similar for these two groups [36.2 wk (SD 1.9) versus $36.4 \mathrm{wk}$ (SD 2.7), $p>0.05$ ].

There was a strong association between bradycardias and both apneic pauses and desaturations (Fig. 2): $143(86 \%)$ of the 166 bradycardias associated with interpretable $\mathrm{SaO}_{2}$ signal (i.e. with 
undisturbed pulse wave forms) were accompanied by a fall in $\mathrm{SaO}_{2}$ to $\leq 80 \%$, and $143(83 \%)$ of the 172 bradycardias associated with interpretable airflow and breathing movement signals were accompanied by an apneic pause. Of these, $129(90 \%)$ showed a cessation of both breathing movements and airflow, and 14 (10\%) showed a cessation of airflow with continued breathing movements, two of these being mixed apneas. Sixteen of the 23 bradycardias not associated with a fall in $\mathrm{SaO}_{2}$ to $\leq 80 \%$ showed falls to between 81 and $89 \%$; in the remaining seven, $\mathrm{SaO}_{2}$ stayed $\geq 90 \%$. One hundred thirteen bradycardias were associated with both a desaturation and an apneic pause. An example of one of these latter bradycardias is given in Figure 1. The bradycardias that were associated with uninterpretable signal (for $\mathrm{SaO}_{2}$ signal, $n=27$ in 16 infants, and for airflow/breathing movement signal, $n=21$ in 15 patients) were not associated with any particular clinical feature.

Measurements during bradycardias (Table 1). The median bradycardia duration was $6.4 \mathrm{~s}(4.0-33.4)$. The median durations of the apneic pauses and desaturations associated with these bradycardias were longer than the average durations reported for this age group, inasmuch as they were similar to the median duration of the longest apneic pause and desaturation found [median 10.0 versus $10 \mathrm{~s}$ and 7.5 versus $5.1 \mathrm{~s}$, respectively, (14, 15)].

Analysis of the time intervals between bradycardias and apneic pauses showed that almost all bradycardias $(97 \%)$ commenced after the onset of the apneic pauses, although usually after only a brief interval: the IQR was 2.2 to $7.5 \mathrm{~s}$. In most instances $(86 \%)$, the bradycardias also began after the onset of the fall in $\mathrm{SaO}_{2}$. This was predominantly because the median interval between the onset of apnea and that of desaturation was short $(0.8$

Table 1. Measurements made during bradycardias*

\begin{tabular}{lccc}
\hline \multicolumn{1}{c}{ Variable } & Median & Range & IQR \\
\hline $\begin{array}{l}\text { Lowest IHR during bradycardias } \\
\text { of } \geq 4 \text { s duration (bpm) }\end{array}$ & 69 & $33-97$ & $60-78$ \\
$\begin{array}{l}\text { Duration of bradycardias } \geq 4 \mathrm{~s} \text { in } \\
\text { duration (s) }\end{array}$ & 6.4 & $4.0-33.4$ & $5.0-9.3$ \\
$\begin{array}{l}\text { Duration of apneic pauses ( } \geq 4 \mathrm{~s}) \\
\text { associated with bradycardia (s) }\end{array}$ & 10.0 & $4.0-38.0$ & $7.0-13.0$ \\
$\begin{array}{l}\text { Duration of desaturations associ- } \\
\text { ated with bradycardia (s) }\end{array}$ & 7.5 & $0.3-32.2$ & $4.0-11.0$ \\
$\begin{array}{l}\text { Lowest SaO during these desatu- } \\
\text { rations (\%) }\end{array}$ & 65 & $10-80$ & $56-72$ \\
$\begin{array}{l}\text { Interval between onset of apneic } \\
\text { pause and onset of bradycardia } \\
\text { (s) }\end{array}$ & +4.8 & $-4.0-+14.0$ & $+2.2-+7.5$ \\
$\begin{array}{l}\text { Interval between onset of apneic } \\
\text { pause and onset of desaturation } \\
\text { (s) (not corrected for lung-toe } \\
\text { circulation time) }\end{array}$ & 5.2 & $0.0-15.0$ & $3.2-6.8$ \\
$\begin{array}{l}\text { Interval between onset of desatu- } \\
\text { ration and onset of bradycardia } \\
\text { (s) (not corrected for lung-toe }\end{array}$ & 0.0 & $-11.6-+14.0$ & $-1.8-+2.5$ \\
$\begin{array}{l}\text { circulation time) } \\
\text { Interval between end of apneic } \\
\text { pause and onset of increase in } \\
\text { SaO (to calculate lung-toe cir- } \\
\text { culation time) (s) }\end{array}$ & 4.3 & $2.6-6.4$ & $3.5-5.0$ \\
$\begin{array}{l}\text { Interval between onset of apneic } \\
\text { pause and onset of desatura- } \\
\text { tion, corrected for lung-toe cir- } \\
\text { culation time (s) }\end{array}$ & +0.8 & $-4.9-+11.5$ & $-1.4-+2.6$ \\
$\begin{array}{l}\text { Interval between onset of desatu- } \\
\text { ration and onset of bradycar- } \\
\text { dia, corrected for lung-toe cir- } \\
\text { culation time (s) }\end{array}$ & -4.2 & $-15.1-+9.5$ & $-6.7--2.1$ \\
\hline & & & \\
\hline Results of the individual meas & & & \\
\hline
\end{tabular}

* Results of the individual measurements are presented as medians. ranges, and IQR. s), with $\mathrm{SaO}_{2}$ during 45 bradycardias (40\%) beginning to fall even before the apneic pauses. Values were corrected for lung-toe circulation times (Table 1).

\section{DISCUSSION}

This study was performed to analyze the temporal relationships between bradycardias, apneic pauses, and desaturations. We found that 83 and $86 \%$ of bradycardias were accompanied by an apneic pause or a desaturation, respectively, and that it was predominantly the relatively prolonged desaturations and apneic pauses that were associated with a bradycardia. We also observed that the bradycardias mostly began after the onset of the apneic pauses and after the onset of the fall in $\mathrm{SaO}_{2}$. Finally, we observed a very short median interval $(0.8 \mathrm{~s})$ between the onsets of apneic pauses and desaturations.

Unlike previous investigators $(8,16)$, we corrected the above temporal relationships for the time it took for the blood to travel from the lung (the site where any change in $\mathrm{SaO}_{2}$ due to a change in $\mathrm{O}_{2}$ uptake will have occurred first) to the toe (the site where this change was registered by the pulse oximeter). There are no published data on lung-toe circulation time in preterm infants; however, we have previously estimated it by measuring the interval that elapsed from the first breath following an apneic pause to the onset of the subsequent increase in $\mathrm{SaO}_{2}(1,13)$ and used the same method in the present study. As circulation time was probably abnormal in the episodes observed, all of which included bradycardia, the correction factor was obtained from those desaturations (the large majority) not associated with bradycardia. We can thus be reasonably certain that we have not overestimated lung-toe circulation times and, as a result, underestimated the intervals observed between the onsets of apnea and of desaturation. This is particularly because published values for total circulation time in neonates [mean $10.2 \mathrm{~s}(17)$ ] correspond well to our results for lung-toe circulation time (median $4.3 \mathrm{~s}$ ), considering that the latter is about one half of the former. We may, however, have overcorrected our results on the relationship between hypoxemia and bradycardia, because the time it took for the blood to travel from the lungs (where hypoxemia commenced) to the carotid bodies (where it was detected by the peripheral chemoreceptors) could have been subtracted. We do not feel, however, that this has significantly altered our results on the sequence of events, inasmuch as lung-carotid body circulation time can only be a small fraction of lung-toe circulation time.

We used a bradycardia definition that was not fixed but took account of each infant's baseline heart rate. However, as it happens, our median bradycardia threshold $(99 \mathrm{bpm})$ was similar to that commonly used in clinical practice (100 bpm).

The temporal relationships of bradycardia to apnea and hypoxemia could not be studied in 21 and 27 episodes, respectively, because they were associated with uninterpretable $\mathrm{SaO}_{2}$ and/or breathing signal. We do not feel, however, that the omission of these bradycardias has resulted in any selection bias, because they were fairly equally distributed among individual recordings and were not associated with any specific clinical feature.

We observed a short (median $4.8 \mathrm{~s}$ ) interval between apnea and bradycardia. This may appear to support previous suggestions that the bradycardia occurs as a reflex response to the cessation of lung inflation $(6,7)$. Why, then, did most bradycardias occur only when apnea was associated with hypoxemia, and why did bradycardia almost always follow the onset of hypoxemia rather than precede it? These observations become comprehensible if one assumes a cause-and-effect relationship between hypoxemia and bradycardia. Such a relationship could, for example, be mediated via the peripheral chemoreceptors (18). But why was it apparently not the hypoxemia, per se, but its coincidence with an apneic pause that resulted in the development of bradycardia? The answer to this may be found in a study by Angell-James and Daly (19). These authors performed cross- 
perfusion studies in dogs and showed that the fall in heart rate was far more pronounced when there was a combination of both apnea and hypoxemic excitation of arterial chemoreceptors than with either apnea or hypoxemia alone. They concluded that the appearance of bradycardia during apneic asphyxia is dependent upon there being no overriding effect from the pulmonary inflation reflex, which is known to cause an increase in heart rate (19). One possible explanation for the observed episodes of bradycardia in this study is, therefore, that they were caused by hypoxemic stimulation of the carotid bodies, and that the resultant effects on heart rate were potentiated by the concomitant cessation of lung inflation during the apneic pauses.

A somewhat surprising finding was the brevity of the interval between the onset of apnea and the onset of the fall in $\mathrm{SaO}_{2}$. In fact, it was this brevity that determined that the bradycardias, despite commencing only a median $4.8 \mathrm{~s}$ after the apneic pauses, still commenced only after $\mathrm{SaO}_{2}$ had already begun to fall. The design of our study does not provide sufficient information to decide whether this early onset of the fall in $\mathrm{SaO}_{2}$ was due to apneic (e.g. hypoventilation) or nonapneic (e.g. intrapulmonary shunting) mechanisms, but results from other studies suggest that nonapneic mechanisms may have been involved $(1,20)$. Another possibility is that apnea, hypoxemia, and bradycardia, or combinations of these phenomena, may have resulted from a set of reflex responses initiated simultaneously.

We consider it unlikely that all bradycardias observed in this study were caused by one mechanism, particularly as this would not explain the 17 and $14 \%$, respectively, of bradycardias that did not follow the general trend, i.e. that were not associated with apnea and/or hypoxemia. It was only the striking coincidence of most bradycardias with both apneic pauses and desaturations that led us to suggest the mechanisms outlined above.

Acknowledgments. The authors thank the parents who allowed us to perform this study: the medical and nursing staff who helped us with the recordings, in particular Drs. Arrowsmith, Bridson, and Salfield; and J. Kelly and P. Mills, who performed initial data analysis.

\section{REFERENCES}

1. Poets CF. Southall DP 1991 Patterns of oxygenation during periodic breathing in preterm infants. Early Hum Dev 26:1-12

2. Livera LN, Spencer SA. Thorniley MS. Wickramasinghe YABD. Rolfe P 1991 Effects of hypoxemia and bradycardia on neonatal cerebral haemodynamics. Arch Dis Child 66:376-380

3. Perlman JM. Volpe JJ 1985 Episodes of apnea and bradycardia in the preterm infant: impact on cerebral circulation. Pediatrics 76:333-338

4. Girling DJ 1972 Changes in heart rate, blood pressure. and pulse pressure during apnoeic attacks in newborn babies. Arch Dis Child 47:405-410

5. Storrs CN 1977 Cardiovascular effects of apnoea in preterm infants. Arch Dis Child 52:534-540

6. Gabriel M, Albani M 1976 Cardiac slowing and respiratory arrest in preterm infants. Eur J Pediatr 122:257-261

7. Vyas H. Milner AD, Hopkin IE 1981 Relationship between apnoea and bradycardia in preterm infants. Acta Paediatr Scand 70:785-790

8. Henderson-Smart DJ, Butcher-Puech MC. Edwards DA 1986 Incidence and mechanism of bradycardia during apnoea in preterm infants. Arch Dis Child 61:227-232

9. Upton CJ, Milner AD, Stokes GM 1992 Episodic bradycardia in preterm infants. Arch Dis Child 67:831-834

10. Poets CF. Stebbens VA. Alexander JR, Arrowsmith WA, Salfield SAW, Southall DP 1992 Arterial oxygen saturation in preterm infants at discharge from the hospital and six weeks later. J Pediatr 120:447-454

11. Richards JM, Alexander JR, Shinebourne EA. de Swiet M. Wilson AJ, Southall DP 1984 Sequential 22-hour profiles of breathing patterns and heart rate in 110 full-term infants during their first 6 months of life. Pediatrics 74:763777

12. Stebbens VA. Poets CF. Alexander JA. Arrowsmith WA. Southall DP 1991 Oxygen saturation and breathing patterns in infancy. I. Fullterm infants in the second month of life. Arch Dis Child 66:569-573

13. Abraham NG, Stebbens VA, Samuels MP, Southall DP 1990 Investigation of cyanotic/apneic episodes and sleep-related upper airway obstruction by longterm non-invasive bedside recordings. Pediatr Pulmonol 8:259-262

14. Hageman JR, Holmes D, Suchy S, Hunt CE 1988 Respiratory pattern at hospital discharge in asymptomatic preterm infants. Pediatr Pulmonol 4:7883

15. Poets CF, Stebbens VA, Alexander JR. Arrowsmith WA. Salfield SAW, Southall DP 1991 Oxygen saturations and breathing patterns in infancy. II. Preterm infants at discharge from special care. Arch Dis Child 66:574-578

16. Hiatt IM. Hegyi T, Indyk L, Dangman BC. James LS 1981 Continuous monitoring of $\mathrm{PO}_{2}$ during apnea of prematurity. J Pediatr 98:288-291

17. Lesser RE, Meyer R. Henderson AT 1952 Circulation times in newborn infants by the fluorescein method. Am J Dis Child 83:645-648

18. Daly $M$ de $B 1986$ Interactions between respiration and circulation. In: Fishman AP (ed) Handbook of Physiology, Section 3, Vol 2, Part 1. American Physiological Society, Bethesda. MD, pp 529-594

19. Angell-James JE, Daly M de B 1969 Cardiovascular responses in apnoeic asphyxia: role of arterial chemoreceptors and the modification of their effects by a pulmonary vagal inflation reflex. J Physiol (Lond) 201:87-104

20. Samuels MP, Poets CF, Stebbens VA, Alexander JR, Southall DP 1992 Oxygen saturation and breathing patterns in preterm infants with severe cyanotic episodes. Acta Paediatr 82:875-880 